\title{
Correlation between Fine-Needle Aspiration Cytology and Histology for Palpable Breast Masses in a Nigerian Tertiary Health Institution
}

\author{
Adetola Olubunmi Daramola, ${ }^{1}$ Mosebolatan Olatokunboh Odubanjo, ${ }^{1}$ \\ Fred John Obiajulu, ${ }^{2}$ Nzechukwu Zimudo Ikeri, ${ }^{2}$ and Adekunbiola Aina Fehintola Banjo ${ }^{1}$ \\ ${ }^{1}$ Department of Anatomic and Molecular Pathology, Lagos University Teaching Hospital and College of Medicine, \\ University of Lagos, PMB 12003, Idi-Araba, Lagos, Nigeria \\ ${ }^{2}$ Department of Anatomic and Molecular Pathology, Lagos University Teaching Hospital, PMB 12003, Idi-Araba, Lagos, Nigeria
}

Correspondence should be addressed to Adetola Olubunmi Daramola; detoladaramola@gmail.com

Received 17 July 2015; Accepted 17 September 2015

Academic Editor: Vladimir F. Semiglazov

Copyright ( 2015 Adetola Olubunmi Daramola et al. This is an open access article distributed under the Creative Commons Attribution License, which permits unrestricted use, distribution, and reproduction in any medium, provided the original work is properly cited.

\begin{abstract}
Background. Management of breast lumps can be challenging in resource poor settings. Fine-needle aspiration cytology (FNAC) especially when used with cell block can help improve affordability for the patients. Objective. To determine the diagnostic accuracy of FNAC of palpable breast lesions within a 5-year period. Methods. The findings obtained from FNAC of palpable breast lumps seen at the FNAC clinic of our department from January 2007 to December 2011 were retrieved and correlated with findings on histology of excisional biopsies. Results. A total of 1790 patients had FNAC of breast lumps during the 5 -year period; 436 of them subsequently had biopsies. Our results compare favourably with the measures of test performance of the UK NHS Breast Screening Programme shown in brackets: absolute sensitivity $95.4 \%$ (>70\%), complete sensitivity $99.2 \%$ (>90\%), full specificity $88.9 \%$ ( $>65 \%)$, positive predictive value $99.6 \%(>99 \%)$, false-negative rate $0.8 \%(<4 \%)$, false-positive rate $0.4 \%(<0.5 \%)$, inadequate rate $3.2 \%(<15 \%)$, and suspicious rate $10.2 \%(<15 \%)$. Conclusion. Breast FNACs compare very well with histology of excisional biopsies and in experienced hands are extremely useful in the management of breast lumps. Further studies assessing the diagnostic accuracy of FNAC and cell blocks in our setting are recommended.
\end{abstract}

\section{Introduction}

Breast cancer is the commonest malignancy in women worldwide and the preoperative evaluation of breast lumps is an essential part of the management of breast lesions $[1,2]$. The use of core needle biopsy in the management of palpable breast lumps in recent times has been increasing $[3,4]$. This is because core needle biopsies are less invasive than open biopsy, and vacuum assisted biopsy devices have been developed to produce larger specimen for analysis [4]. Core needle biopsy is however not without disadvantages. These include a high cost (when compared with FNAC), long tissue processing time, patient discomfort such as pain and haematoma, and the risk of seeding of the tumor along the needle track $[2,5]$. The triple test which comprises clinical, radiological, and pathological assessment however remains an excellent tool in the assessment of palpable breast lumps. Its diagnostic accuracy exceeds $99 \%$ when all three modalities are concordant $[2,6,7]$.

Most countries have now adopted this triple assessment approach (clinical, radiological, and pathological) to breast diagnosis, with FNAC as the first-line pathological investigation in both screening and symptomatic populations, with the exception of cases where microcalcifications are present [8]. However, some variation in practice exists. When all three assessments are concordant, final treatment of malignant lesions (mastectomy, chemotherapy, and/or radiotherapy) may proceed on the basis of FNAC, without a tissue biopsy; some others insist on a core needle biopsy for all index lesions [8]. In most Nigerian hospitals, tissue biopsies are requested 
before mastectomy even when the lesion is malignant on FNAC, thus increasing the demand on scarce monetary resources. In a resource-limited setting such as ours, the case could be made for proceeding to mastectomy without requesting tissue biopsies, particularly if FNAC is combined with cell block preparations, to further increase its diagnostic accuracy and versatility. Smears and cell blocks can be tested for ER and PR using immunocytochemistry while HER2 testing can only be done by FISH as HER2 immunocytochemistry is unreliable even in the best centres.

FNACs, especially in the hands of experienced cytopathologists, have high diagnostic accuracy, as high as $98.9 \%$ in some series $[9,10]$. Diagnostic accuracy of FNAC is further increased with cell block preparations approaching $100 \%$ in a particular study [11], making FNAC the most reliable element of the triple test in cases where the three modalities are nonconcordant [6].

In addition to its high diagnostic accuracy, FNAC offers advantages such as minimal invasiveness, minimal discomfort, cost-effectiveness, and rapidity of results when compared with core needle biopsy $[5,12,13]$. FNAC is therefore an extremely vital tool in the evaluation of palpable breast lumps in resource-limited settings.

The objective of this study is to determine the diagnostic accuracy of FNAC in the evaluation of palpable breast masses in LUTH.

\section{Materials and Methods}

Records of FNAC results of palpable breast lumps seen at the FNAC clinic of the Department of Anatomic and Molecular Pathology of the Lagos University Teaching Hospital (LUTH) from 2007 to 2011 were retrieved from the database. FNAC was performed for all the cases using a $23 \mathrm{G}$ needle attached to $20 \mathrm{~mL}$ disposable plastic syringes smeared on standard microscope glass slides, fixed with alcohol, and stained with Haematoxylin and Eosin (H\&E), modified Giemsa, and Papanicolaou (Pap) stains. These cases were reported using a 5-tier system: C1 for inadequate; C2 for benign; C3 for suspicious, probably benign; $\mathrm{C} 4$ for suspicious, probably malignant; and C5 for malignant breast lesions.

Records of subsequent excisional biopsies or mastectomies were also retrieved from the pathology database and compared with the cytology results for correlation (Figure 1). Quality assurance statistical parameters were calculated according to the NHS Breast Screening Programme (NHSBSP) guidelines [2].

Cases with missing data were excluded from the study.

\section{Results}

FNAC was requested for a total of 1790 breast lumps during the study period. Of these, 1301 were benign, 250 were malignant, 181 were equivocal, and 58 were inadequate (Figure 2). Four hundred and thirty-six (436) of the 1790 cases subsequently had biopsies, a biopsy rate of $24.4 \%$ (Figure 3 ).

The correlation of cytological and histological diagnoses is shown in Table 1. Over $90 \%$ of cases from FNAC (96.3\%) were confirmed to be malignant by histology, and $99.5 \%$ were
TABLE 1: Correlation of cytological and histological diagnosis.

\begin{tabular}{lccc}
\hline & Cytology & \multicolumn{2}{c}{ Histology } \\
Diagnosis & Number with follow-up biopsies & Benign & Malignant \\
\hline C1 & 3 & 3 & 0 \\
C2 & 367 & 365 & 2 \\
C3 & 29 & 25 & 4 \\
C4 & 10 & 4 & 6 \\
C5 & 27 & 1 & 26 \\
Total & 436 & 398 & 38 \\
\hline
\end{tabular}

TABLE 2: Comparison of results with UK NHSBSP thresholds of performance.

\begin{tabular}{lccc}
\hline Parameter & Minimum (\%) & Preferred (\%) & $\begin{array}{c}\text { This LUTH } \\
\text { study }\end{array}$ \\
\hline Absolute sensitivity & $>60$ & $>70$ & $95.4 \%$ \\
Complete sensitivity & $>80$ & $>90$ & $99.2 \%$ \\
Full specificity & $>55$ & $>65$ & $88.9 \%$ \\
Positive predictive & $>98$ & $>99$ & $99.6 \%$ \\
value & $<6$ & $<4$ & $0.8 \%$ \\
False-negative rate & $<1$ & $<0.5$ & $0.4 \%$ \\
False-positive rate & $<25$ & $<15$ & $3.2 \%$ \\
Inadequate rate & $<10$ & $<5$ & $0 \%$ \\
Inadequate rate from & $<$ cancers & $<15$ & $10.1 \%$ \\
Suspicious rate & $<20$ &
\end{tabular}

confirmed to be benign. $82.8 \%$ suspicious but possibly benign on FNAC were found to be benign on histology, and $60 \%$ of cases suspected to be malignant were found to be malignant.

Quality assurance statistics were calculated according to the UK NHSBSP guidelines and the values are shown in Table 2. The absolute sensitivity, the number of carcinomas diagnosed as such on cytology expressed as a percentage of the total number of carcinomas sampled, was $95.4 \%$. The complete sensitivity which is the number of carcinomas that were not definitely negative or inadequate on FNAC expressed as a percentage of the total number of carcinomas was $99.2 \%$. Full specificity, which is the number of correctly identified benign lesions expressed as a percentage of the total number of benign lesions, was $88.9 \%$. The positive predictive value, defined as the number of correctly identified cancers expressed as a percentage of the total number of positive results, was $99.6 \%$.

Correlations of specific diagnoses made on cytology and histology are shown in Table 3. Of 8 cases suspected to be inflammatory on FNAC, 4 were confirmed by histology to be inflammatory, 1 was fibroadenoma, another was fibrocystic changes, 1 was hidrocystoma, and 1 was invasive lobular carcinoma. One case suspected to be a lipoma on cytology was confirmed to be lipoma on histology. The other case was found to consist of normal breast tissue only. 

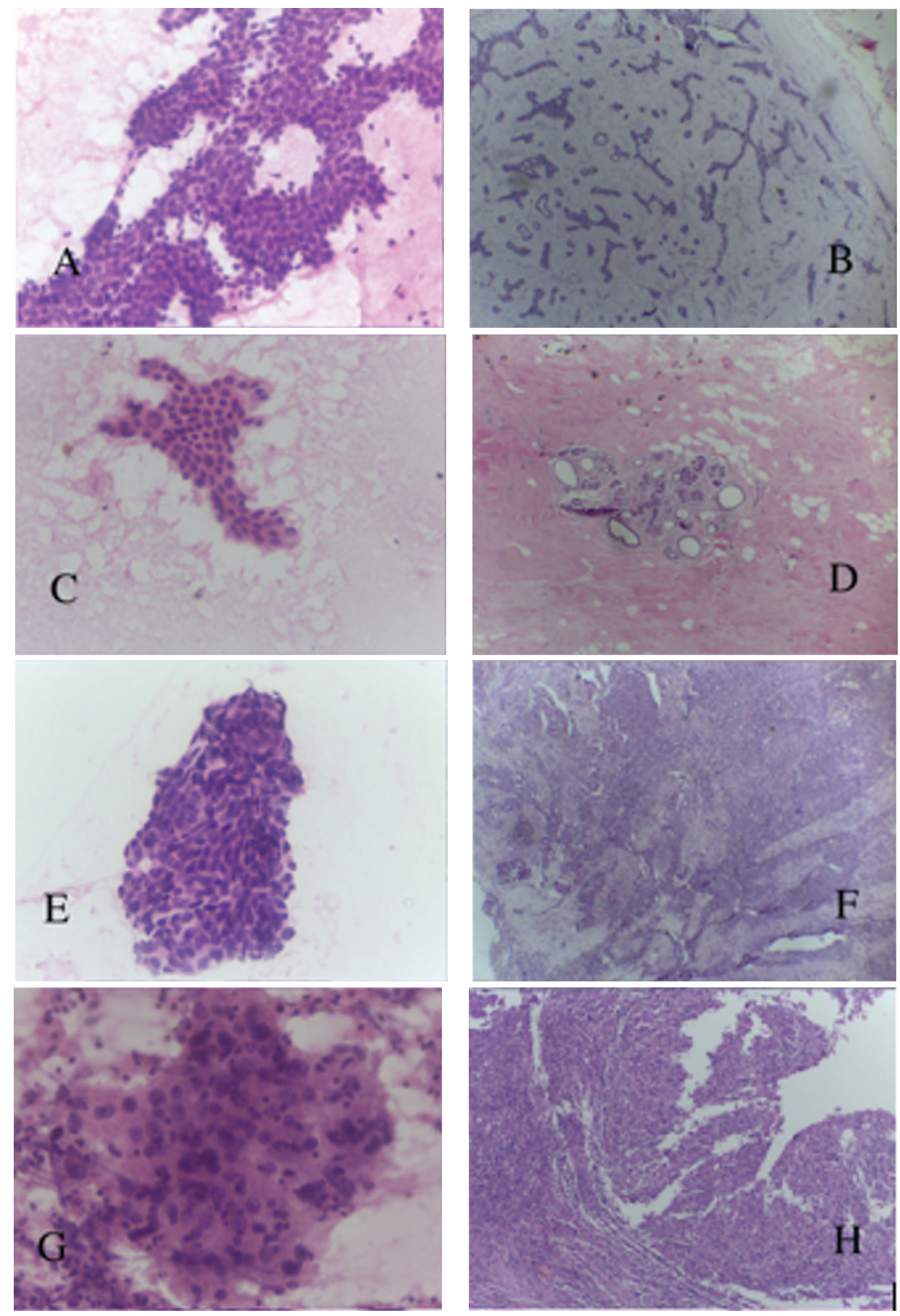

Figure 1: Photomicrograph showing smear preparations diagnosed as C2 (A), C3 (C), C4 (E), and C5 (G) and their corresponding diagnoses: fibroadenoma (B), fibrocystic changes (D), and invasive ductal carcinoma of no special type ((F) and $(\mathrm{H}))$.

\section{Discussion}

FNAC is a useful tool in the preoperative evaluation of breast lumps [2]. Accurate preoperative evaluation is important as it allows for rapid referral of malignant cases for treatment and discharge of benign cases from the clinic and their return to routine follow-up [2]. FNAC can also be used in following up these benign cases except when otherwise indicated. FNAC is accurate, cheap, and easy to perform and is less invasive than core needle biopsies [5].

Quality assurance statistics calculated for this study (Table 2) compare favourably with the UK NHSBSP thresholds of performance and show a high accuracy of FNAC in evaluating breast lumps. Studies from other Nigerian centres also corroborate this finding. In a study done at the Aminu Kano University Teaching Hospital (AKTH), 
TABLE 3: Correlation of specific cytologic and histologic diagnoses.

\begin{tabular}{|c|c|c|c|c|c|c|c|c|}
\hline \multicolumn{2}{|c|}{ Cytology } & \multicolumn{7}{|c|}{ Histology } \\
\hline Diagnosis & Total number & Fibroadenoma & Inflammatory & Fibrocystic change & Normal breast & t Lipoma & Hidrocystomas & $\begin{array}{c}\text { Invasive lobular } \\
\text { carcinoma }\end{array}$ \\
\hline Fibroadenoma & 6 & 6 & - & - & - & - & - & - \\
\hline Inflammatory & 8 & 1 & 4 & 1 & - & - & 1 & 1 \\
\hline $\begin{array}{l}\text { Fibrocystic } \\
\text { change }\end{array}$ & 2 & - & - & 2 & - & - & - & - \\
\hline Lipoma & 2 & - & - & - & 1 & 1 & - & - \\
\hline $\begin{array}{l}\text { Cystic breast } \\
\text { lesions }\end{array}$ & 1 & 1 & - & - & - & - & - & - \\
\hline
\end{tabular}

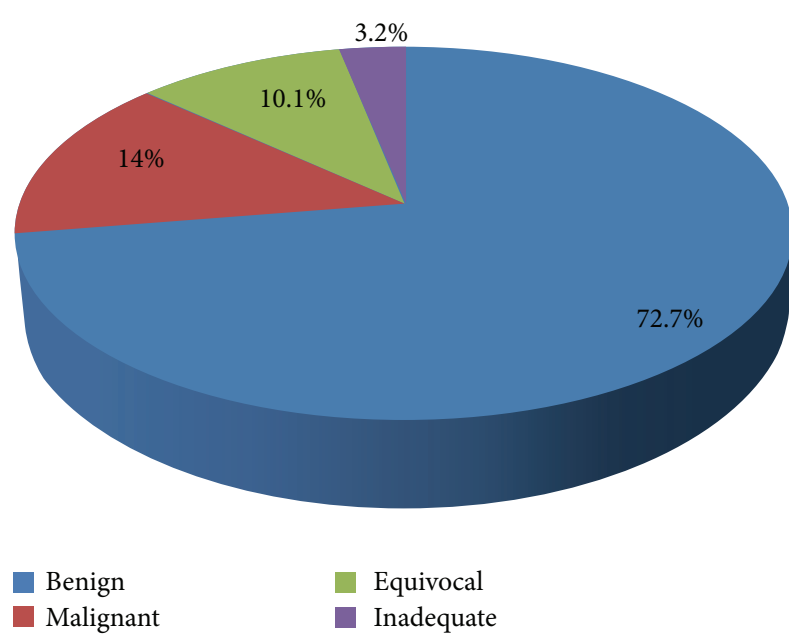

FIGURE 2: Spectrum of cytologic diagnosis.

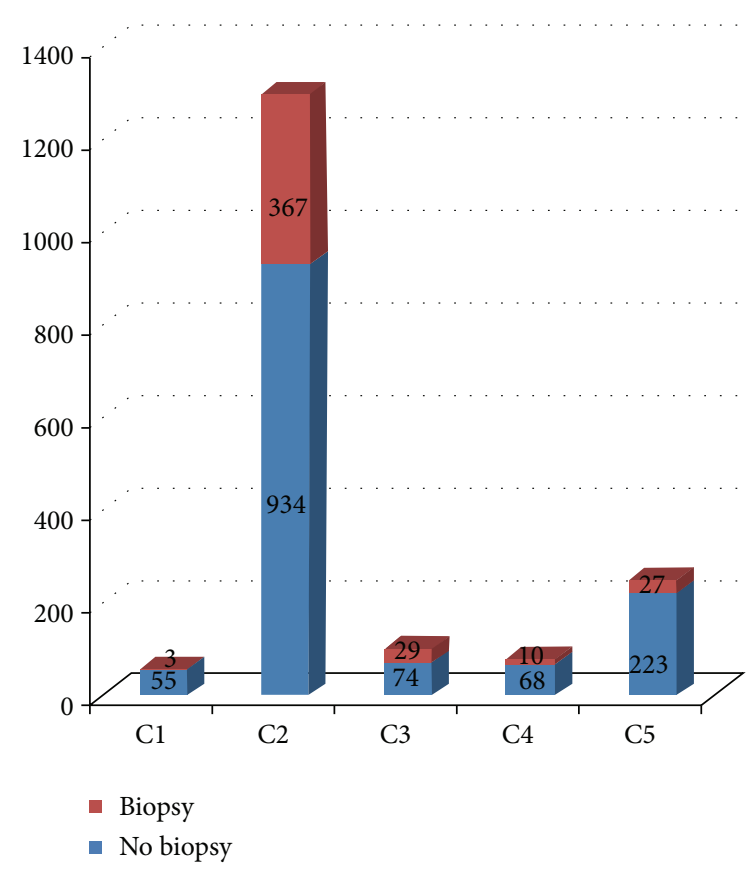

FIGURE 3: Cytology cases with follow-up biopsies. absolute sensitivity was $81 \%$, specificity was $99 \%$, and positive predictive value was $97.7 \%$ [14]. Another done in Benin reported an absolute sensitivity of $84.6 \%$, complete sensitivity of $97.4 \%$, full specificity of $64 \%$, and positive predictive value of $100 \%$ [15]. These studies show the adequacy of FNAC in the evaluation of palpable breast lumps in resource-limited settings.

Our study showed a low frequency of inadequate specimens in line with the NHSBSP thresholds of performance. This is because of the on-site evaluation of the fine-needle aspiration specimens by pathologists using a rapid staining technique (modified Giemsa). On-site evaluation of aspirates has been shown to be accurate and cost-effective [13]. It also reduces the likelihood of being recalled for a repeat FNAC and therefore reduces delay in obtaining results [2].

Missing the lesion on sampling during aspiration is known to be the most common cause of a false-negative cytological diagnosis [2]. Certain carcinomas including lobular carcinoma (responsible for one of the false-negative results in this study, Table 3) may produce such a result [2]. Indeed, FNAC of invasive lobular carcinoma is associated with notoriously high rates of false-negative and equivocal diagnoses [16]. This is because classic invasive lobular carcinoma is more likely to yield a paucicellular smear with subtle atypia and rare single intact epithelial cells [16].

The false-positive case in this study was fibroadenoma with foci of proliferative changes. Fibroadenomas are the commonest cause of false-positive diagnosis in FNAC. This is because of the frequent presence of occasional isolated intact cells with dissociation, epithelial nuclear atypia, and high cellularity [17]. Apocrine metaplasia, multinucleation, and paucicellularity in hyalinized fibroadenomas are additional pitfalls [17].

In this study, 181 out of 1790 FNAC cases were equivocal, giving a suspicious rate of $10.1 \%$. Though this value is within the preferred thresholds of performance, this figure can be reduced further by the use of cell block preparations which were not done in these cases. Cell blocks prepared from residual tissue fluid have been shown to assist in further establishing a more definitive cytopathologic diagnosis [18]. In one study, 3 cases suspicious for malignancy on FNAC were confirmed to be invasive ductal carcinoma with cell block [19]. Other limitations of breast FNAC that can readily be overcome by cell blocks are the difficulty in demonstrating 
invasion and classifying proliferative lesions [20]. ER and PR receptor testing can be reliably performed on both smears and cell blocks obtained from FNA using immunocytochemistry [8]. The results are expressed as the percentage of tumour cells showing nuclear staining while HER2 can only be reliably tested using fluorescent in situ hybridization (FISH).

\section{Conclusion}

Breast FNACs compare very well with histology for excisional biopsies, and, in experienced hands, they are extremely useful in the evaluation of breast lumps. Further studies assessing the diagnostic accuracy of FNAC and cell block preparations in our setting are in progress.

\section{Conflict of Interests}

The authors declare that there is no conflict of interests regarding the publication of this paper.

\section{References}

[1] International Agency for Research on Cancer, "GLOBOCAN 2012: Estimated Cancer Incidence, Mortality and Prevalence Worldwide in 2012," 2015, http://globocan.iarc.fr/Pages/fact_sheets_ population.aspx.

[2] I. O. Ellis, S. Humphreys, M. Michell, S. E. Pinder, C. A. Wells, and H. D. Zakhour, Guidelines for Non-Operative Diagnostic Procedures and Reporting in Breast Cancer Screening, NHS Cancer Screening Programme, Sheffield, UK, 2001.

[3] M. Rosa, A. Mohammadi, and S. Masood, "The value of fine needle aspiration biopsy in the diagnosis and prognostic assessment of palpable breast lesions," Diagnostic Cytopathology, vol. 40, no. 1, pp. 26-34, 2012.

[4] T. Oyama, Y. Koibuchi, and G. McKee, "Core needle biopsy (CNB) as a diagnostic method for breast lesions: comparison with fine needle aspiration cytology (FNA)," Breast Cancer, vol. 11, no. 4, pp. 339-342, 2004.

[5] C. Garbar and H. Curé, "Fine-needle aspiration cytology can play a role in neoadjuvant chemotherapy in operable breast cancer," ISRN Oncology, vol. 2013, Article ID 935796, 5 pages, 2013.

[6] I. Ahmed, R. Nazir, M. Y. Chaudhary, and S. Kundi, "Triple assessment of breast lump," Journal of the College of Physicians and Surgeons Pakistan, vol. 17, no. 9, pp. 535-538, 2007.

[7] A. S. Al-Mulhim, M. Sultan, F. M. Al-Mulhim et al., "Accuracy of the 'triple test' in the diagnosis of palpable breast masses in Saudi females," Annals of Saudi Medicine, vol. 23, no. 3-4, pp. 158-161, 2003.

[8] G. Kocjan, C. Bourgain, A. Fassina et al., "The role of breast FNAC in diagnosis and clinical management: a survey of current practice," Cytopathology, vol. 19, no. 5, pp. 271-278, 2008.

[9] M. H. Bukhari, M. Arshad, S. Jamal et al., "Use of fine-needle aspiration in the evaluation of breast lumps," Pathology Research International, vol. 2011, Article ID 689521, 10 pages, 2011.

[10] S. I. Panjvani, B. J. Parikh, S. B. Parikh et al., "Utility of fine needle aspiration cytology in the evaluation of breast lesions," Journal of Clinical \& Diagnostic Research, vol. 7, no. 12, pp. 27772779, 2013.
[11] S. Basnet and O. P. Talwar, "Role of cell block preparation in neoplastic lesions," Journal of Pathology of Nepal, vol. 2, no. 4, pp. 272-276, 2012.

[12] A. Z. Mohammed, S. T. Edino, O. Ochicha, and S. U. Alhassan, "Value of fine needle aspiration biopsy in preoperative diagnosis of palpable breast lumps in resource-poor countries: a Nigerian experience," Annals of African Medicine, vol. 4, no. 1, pp. 19-22, 2005.

[13] J. F. Nasuti, P. K. Gupta, and Z. W. Baloch, "Diagnostic value and cost-effectiveness of on-site evaluation of fine-needle aspiration specimens: review of 5,688 cases," Diagnostic Cytopathology, vol. 27, no. 1, pp. 1-4, 2002.

[14] I. Yusuf and A. T. Atanda, "Validity of fine needle aspiration cytology of the palpable breast lesions: a teaching hospital experience," Nigerian Journal of Basic and Clinical Sciences, vol. 11, no. 1, pp. 36-40, 2014.

[15] D. E. Obaseki, A. N. Olu-Eddo, and J. O. Ogunbiyi, "Diagnostic accuracy of fine needle aspiration cytology of palpable breast masses in Benin City, Nigeria," West African Journal of Medicine, vol. 29, no. 4, pp. 259-262, 2010.

[16] S. Hwang, O. Ioffe, I. Lee, J. Waisman, J. Cangiarella, and A. Simsir, "Cytologic diagnosis of invasive lobular carcinoma: factors associated with negative and equivocal diagnoses," Diagnostic Cytopathology, vol. 31, no. 2, pp. 87-93, 2004.

[17] G. Tse, H. P. Tan, and F. Schmitt, "Fibroadenoma," in Fine Needle Aspiration Cytology of the Breast: Atlas of Cyto-Histologic Correlates, pp. 65-72, Springer, Heidelberg, Germany, 2013.

[18] N. A. Nathan, E. Narayan, M. M. Smith, and M. J. Horn, "Cell block cytology. Improved preparation and its efficacy in diagnostic cytology," American Journal of Clinical Pathology, vol. 114, no. 4, pp. 599-606, 2000.

[19] S. Basnet and O. P. Talwar, "Role of cell block preparation in neoplastic lesions," Journal of Pathology of Nepal, vol. 2, no. 4, pp. 272-276, 2002.

[20] S. Istvanic, A. H. Fischer, B. F. Banner, D. M. Eaton, A. C. Larkin, and A. Khan, "Cell blocks of breast FNAs frequently allow diagnosis of invasion or histological classification of proliferative changes," Diagnostic Cytopathology, vol. 35, no. 5, pp. 263-269, 2007. 


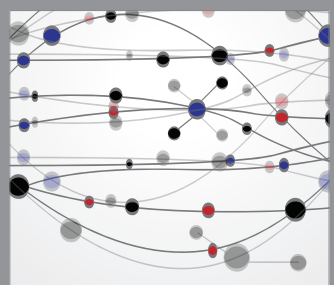

The Scientific World Journal
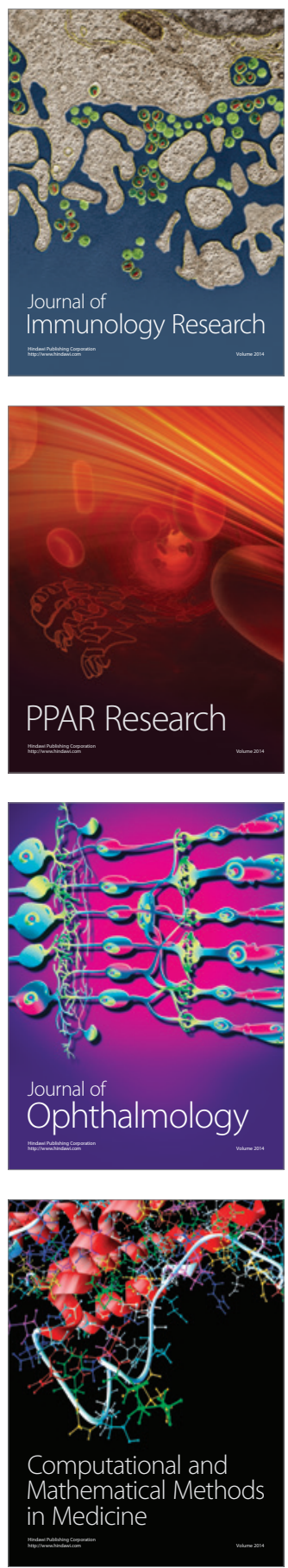

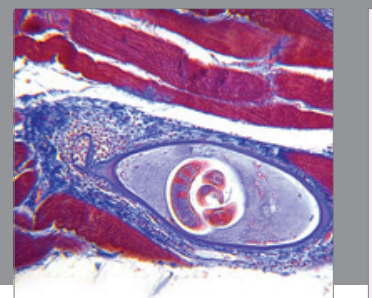

Gastroenterology

Research and Practice
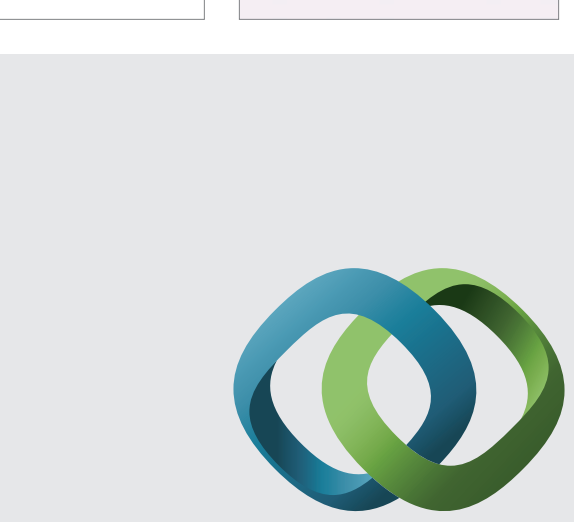

\section{Hindawi}

Submit your manuscripts at

http://www.hindawi.com
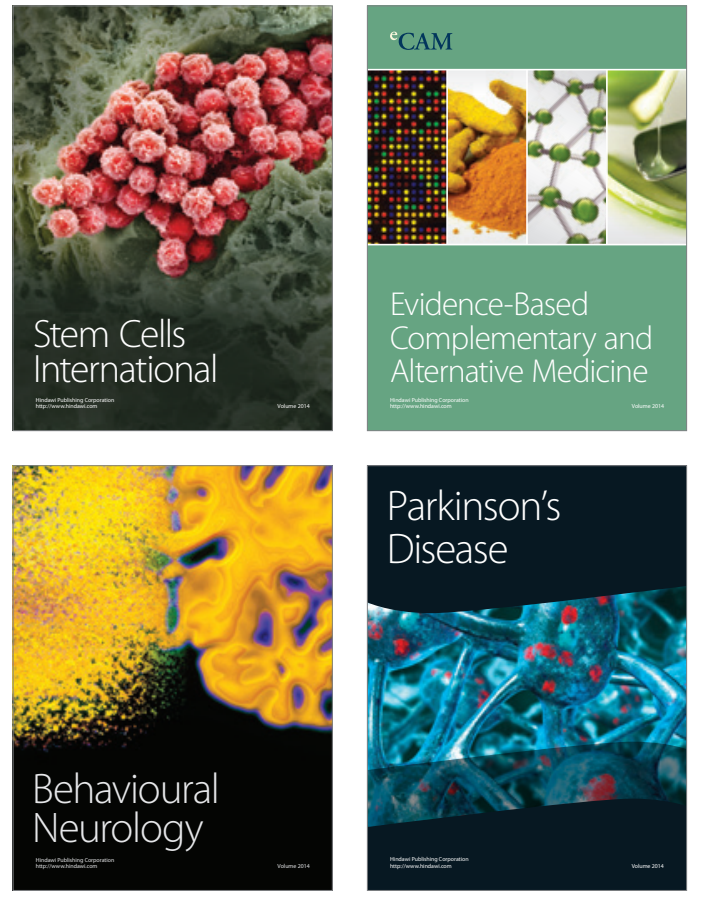
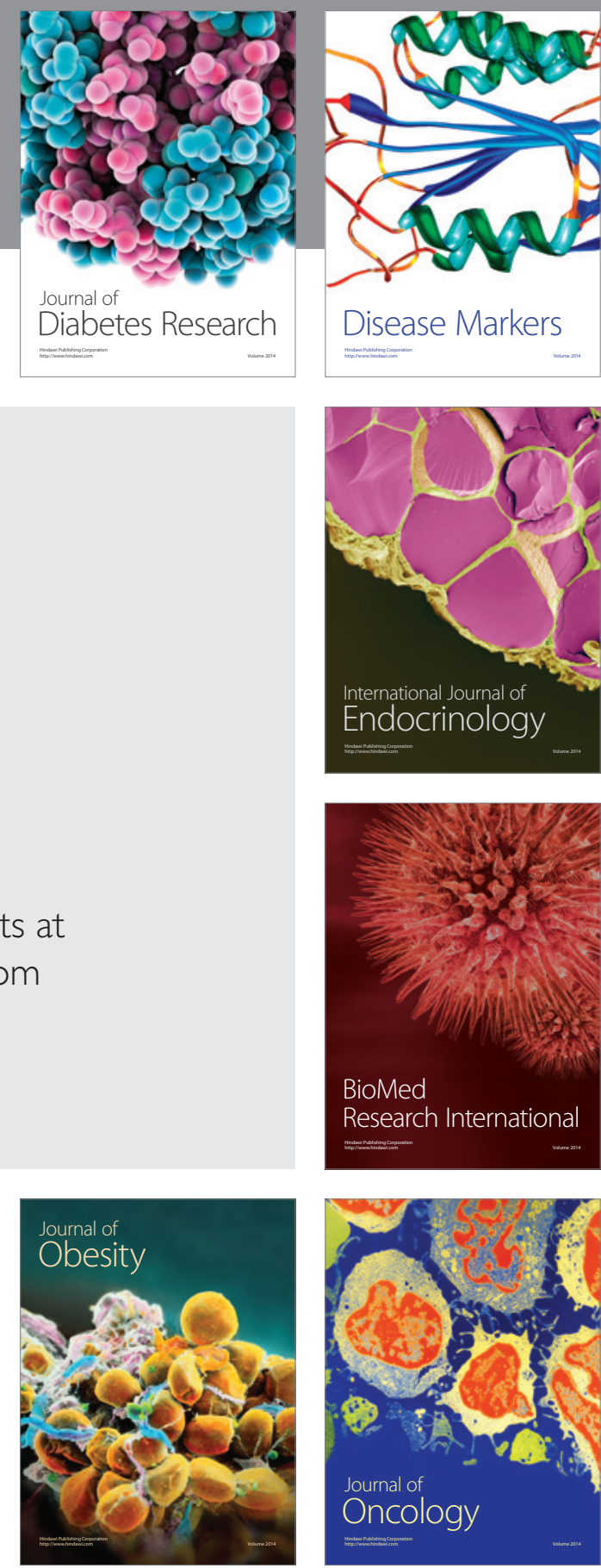

Disease Markers
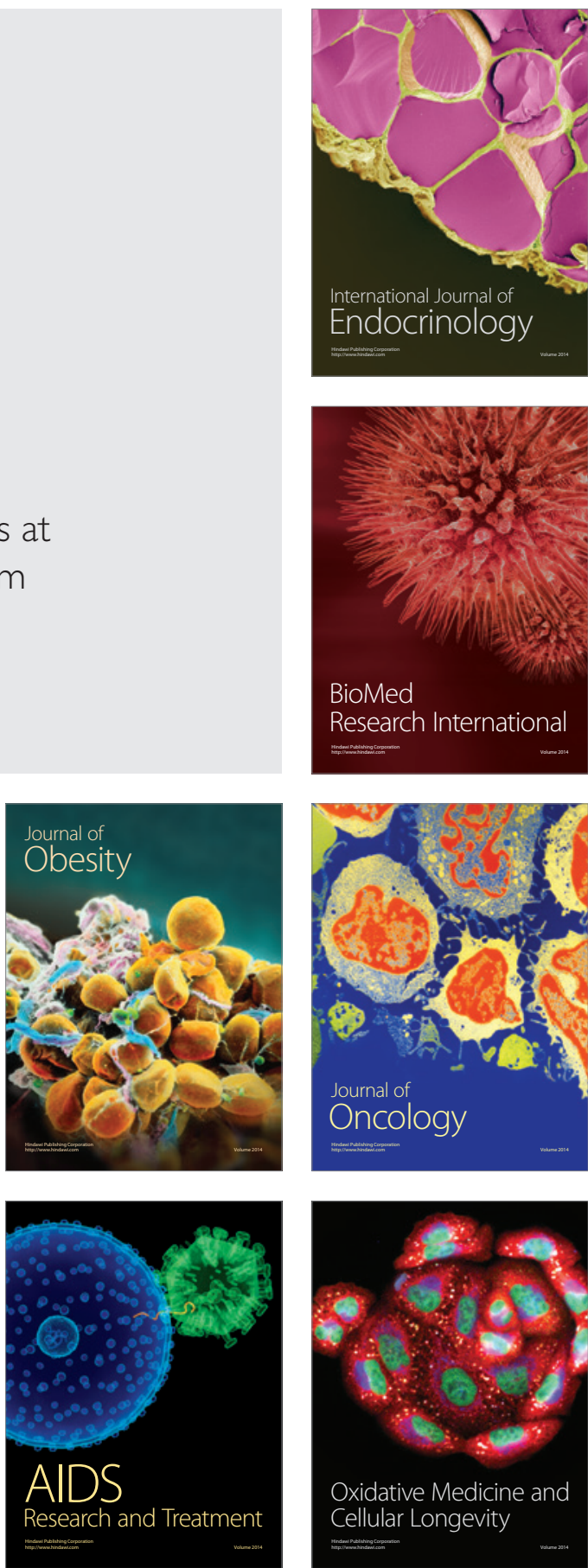